\section{Aggregatibacter actinomycetemcomitans y Fusobacterium nucleatum en biopelículas subgingivales de pacientes brasileños con y sin enfermedad periodontal: comparación de dos métodos de detección}

\section{Aggregatibacter actinomycetemcomitans and Fusobacterium nucleatum in subgingival biofilms from Brazilian patients with and without periodontal disease: comparison of two detection methods}

\section{Artículo Original}

Veruska de João Malheiros ${ }^{1, a}$, Mario Julio Avila-Campos ${ }^{2, b}$

${ }^{1}$ Universidade Paranaense, Faculdade de Odontologia. Paraná, PR, Brasil.

2 Universidade de São Paulo, Laboratório de Anaeróbios, Departamento de Microbiologia, Instituto de Ciências Biomédicas. São Paulo, SP, Brasil.

a Cirujano Dentista y Magister en Microbiología

b Doctor en Microbiología

Correspondencia:

Mario Julio Avila-Campos

Correo electrónico: mariojac@usp.br Av. Prof. Lineu Prestes, 1374, 05508-900, São Paulo, SP, Brasil.

Coautora:

Veruska de João Malheiros

vjmalhei@usp.br

Conflicto de intereses: Los autores declaran no tener conflictos de interés.

Fuente de financiamiento: Este estudio fue financiado por la Fundación de Amparo à Pesquisa do Estado de São Paulo (FAPESP) Proceso No. 2013/13652-6

Fecha de recepción: 05/07/18

Fecha de aceptación: 23/08/18

\begin{abstract}
Resumen
Objetivo: Realizar la detección comparativa de cepas de $A$. actinomycetemcomitans y $F$. nucleatum de muestras subgingivales por los métodos de cultivo y de reacción en cadena de la polimerasa (PCR). Métodos: Fueron evaluados 50 pacientes con periodontitis crónica $(\mathrm{P})$ y 50 pacientes sanos (S). Las muestras fueron colectadas de bolsas periodontales y surcos gingivales. El cultivo bacteriano fue realizado en agar tripticasa de soya-suero de caballo-bacitracina-vancomicina, e incubado en anaerobiosis. La identificación bacteriana fue por métodos bioquímicos de fermentación de carbohidratos y por PCR. Resultados: Por el método de cultivo, de las 50 muestras de periodontitis, 9 (18\%) fueron positivas para $A$. actinomycetemcomitans aislándose 17 cepas. También, de esas muestras, 10 (20\%) fueron positivas para F. nucleatum aislándose 19 cepas. De las 50 muestras de pacientes sanos, solamente $1(2 \%)$ fue positiva para $A$. actinomycetemcomitans obteniéndose 2 cepas, y 12 (24\%) positivas para $F$. nucleatum con 18 cepas. Por PCR fueron observadas diferencias en la detección de $A$. actinomycetemcomitans, entre los tres pares de partidores utilizados, para muestras de bolsa periodontal y surco gingival: partidor AA, $96 \%$ y $86 \%$; partidor FU, $48 \%$ y $42 \%$; y partidor ASH, $24 \%$ y $6 \%$. Los porcentajes de detección para $F$. nucleatum de muestras de $\mathrm{P}$ y $S$ fueron: partidor FN-5047, 36\% y 18\%; y partidor 505-S, 8\% para ambas muestras colectadas. Cepas de A. actinomycetemcomitans biotipo II fueron las más prevalentes. Conclusiones: EL método de PCR fue más sensible y específico en la detección bacteriana que el cultivo.
\end{abstract}

Palabras clave: Aggregatibacter actinomycetemcomitans; Fusobacterium nucleatum; Bacterias anaerobias gram-negativas; Periodontitis. 


\begin{abstract}
Objective: A comparative detection of strains of A. actinomycetemcomitans and F. nucleatum directly from subgingival samples was performed by culture and polymerase chain reaction (PCR) methods. Methods: Fifty patients with chronic periodontitis (P) and 50 healthy patients $(S)$ were evaluated. Subgingival samples were collected from periodontal pockets and gingival sulcus. Bacterial culture was performed on trypticase soy-horse serum-bacitracin-vancomycin agar and incubated in anaerobiosis. Bacterial identification was done by biochemical methods of carbohydrate fermentation and by PCR. Results: By culture method, of the 50 samples of periodontitis, 9 (18\%) were positive for $A$. actinomycetemcomitans isolating 17 strains. Also, of these samples, $10(20 \%)$ were positive for $F$. nucleatum isolating 19 strains. Of the 50 samples from healthy patients, only $1(2 \%)$ was positive for A. actinomycetemcomitans, obtaining 2 strains, and $12(24 \%)$ positive for $F$. nucleatum with 18 strains. Differences were observed in the detection of A. actinomycetemcomitans among the three pairs of primers used, for periodontal pocket and gingival sulcus samples: primer AA, $96 \%$ and $86 \%$; primer $\mathrm{FU}, 48 \%$ and $42 \%$; and primer ASH, 24\% and 6\%. The percentages of detection for $F$. nucleatum of samples from $\mathrm{P}$ and $\mathrm{S}$ were: primer FN-5047, 36\% and 18\%; and primer 505-S, 8\% for both samples collected. Strains of $A$. actinomycetemcomitans biotype II were the most prevalent. Conclusions: The PCR method was more sensitive and specific in the bacterial detection than the culture.
\end{abstract}

Keywords: Aggregatibacter actinomycetemcomitans; Fusobacterium nucleatum; Gram-negative anaerobic bacteria; Periodontitis.

\section{Introducción}

De todos los procesos infecciosos que ocurren en la cavidad bucal del ser humano, la enfermedad periodontal es considerada relevante por su elevada prevalencia y por la pérdida dental en individuos adultos jóvenes ${ }^{1}$. Las enfermedades periodontales se caracterizan por su naturaleza multifactorial y polimicrobiana, donde se observa la participación de organismos específicos (periodontopatógenos Gram-negativos anaerobios) e inespecíficos (comensales) ${ }^{2}$.

Aggregatibacter actinomycetemcomitans (A. actinomycetemcomitans) y Fusobacterium nucleatum (F. nucleatum) son importantes periodontopatógenos que están implicados en la patogénesis de las periodontitis, y en otros procesos infecciosos de origen endógeno ${ }^{3}$. El $A$. actinomycetemcomitans es considerado un cocobacilo Gram-negativo, capnofílico e inmóvil, y es aislado de diversos procesos infecciosos bucales y extra-bucales ${ }^{4,5}$. Debido a su participación en los procesos periodontales, este microorganismo es considerado relevante en el estado de la enfermedad, por ser encontrado en número elevado y por la producción de diversos factores de virulencia, tales como la habilidad de adherir e invadir tejidos periodontales, producción de colagenasa, lipopolisacárido, y leucotoxina, la cual se constituye el principal mecanismo agresor de esta bacteria, destruyendo células inmunes del huésped ${ }^{6,7}$.

En la última década, la literatura ha mostrado la enorme importancia de $A$. actinomycetemcomitans y $F$. nucleatum debido al papel que desempeñan en las patologías bucales que afectan el tejido periodontal. F. nucleatum se constituye un bacilo fusiforme, Gram-negativo, anaerobio estricto e inmóvil, y es también aislado de diferentes periodontopatías con pérdidas óseas activas ${ }^{7}$. Esta bacteria también forma parte de la microbiota residente de la cavidad bucal humana y es considerada la segunda especie anaerobia bucal más aislada de procesos infecciosos humanos ${ }^{8}$. Adicionalmente, F. nucleatum tiene un importante papel en la formación de la biopelícula dental, formando un puente entre los colonizadores iniciales y tardíos, y por la capacidad de co-agregación con diferentes microorganismos de la cavidad bucal ${ }^{9}$.

En la microbiología bucal es esencial la identificación y caracterización de los microorganismos que participan de las diferentes infecciones bucales. Varios son los métodos microbiológicos y de detección fenotípica o genotípica que son usados para caracterizar patógenos periodontales y diferenciarlos de cepas comensales. Entre ellos se pueden mencionar el método tradicional de cultivo, considerado por la literatura extranjera como el método de referencia o "patrón oro", debido a que los nuevos métodos de detección microbiana deben ser comparados con ese método, cuanto a su eficacia y sensibilidad ${ }^{10,11}$. El cultivo posee algunas ventajas que permite el análisis de las características fenotípicas y la determinación de la susceptibilidad a los antimicrobianos. Por otro lado, este método es costoso, lleva tiempo, y falla para detectar organismos exigentes en términos nutricionales y atmosféricos ${ }^{12,13}$.

Con el aparecimiento de métodos moleculares para la detección rápida de microorganismos, los periodontopatógenos son estudiados de forma más precisa. Métodos como sondas de DNA, checkerboard, y la reacción en cadena de la polimerasa (PCR), son utilizados por diferentes investigadores para determinar la presencia microbiana en muestras clínicas periodontales. Dentro de esos métodos, el PCR se destaca por la rápida detección, por su sensibilidad, especificidad y reproductibilidad en la identificación y distinción de periodontopatógenos 14,15. También, el uso del PCR ayuda a determinar el rol de bacterias específicas en las enfermedades periodonta- 
les por su habilidad de detectar especies de poblaciones microbianas mixtas.

De esta forma, considerando la necesidad de determinar formas rápidas y eficaces para el diagnóstico de bacterias periodontopatogénicas, y buscando padronizar los procesos de detección de esos microorganismos, el presente estudio tuvo como objetivo detectar comparativamente la presencia de cepas de $A$. actinomycetemcomitans y $F$. nucleatum, directamente de muestras clínicas subgingivales, utilizándose las técnicas de cultivo y de PCR.

\section{Métodos}

Diseño de estudio. Se diseñó un estudio comparativo de dos técnicas de diagnóstico para dos microorganismos bucales. Para el tamaño de la población en estudio, se seleccionaron 50 pacientes con periodontitis crónica (P) y 50 pacientes sanos sin enfermedad periodontal (S). Todos los participantes tuvieron entre 20 y 60 años de edad, sin distinción de género y raza. Todos los participantes fueron inscritos en la Clínica de Periodoncia de la Facultad de Odontología de la Universidad de São Paulo (FOUSP), examinados y seleccionados por un especialista en periodoncia.

Selección de la muestra. Inicialmente, los participantes $\mathrm{P}$ y $\mathrm{S}$ fueron sometidos a un examen periodontal completo que fue realizado por un único especialista en periodoncia. Fueron colectados los valores de perdida dental, índice de placa (escore total de placa), sangrado al sondaje (escore de sangrado total), profundidad de sondaje, recesión gingival y nivel de adherencia clínica de seis sitios por diente (sitio mesial, medio y distal de las superficies bucal, lingual y/o palatino), excluyendo los terceros molares, usándose una sonda periodontal manual (PCP UNC-15; Hu-Friedy). Las características de los pacientes están presentadas en la Tabla 1. Los pacientes fueron diagnosticados con periodontitis crónica severa y generalizada mostrando perdida de adherencia $\geq 5 \mathrm{~mm}$ en $30 \%$ de los sitios periodontales ${ }^{16}$. Ninguno de los participantes ( $\mathrm{P}$ y $\mathrm{S}$ ) seleccionados para este estudio, utilizó antimicrobianos. Los criterios de exclusión fueron: la historia de automedicación, diabetes, enfermedad autoinmune u otras patologías sistémicas, así como también, algún tratamiento periodontal o antibiótico por lo menos tres meses antes de las colectas. También, todos ellos, firmaron a voluntad el documen- to de consentimiento informado de participación para este estudio, aprobado por el Comité de Ética del Instituto de Ciencias Biomédicas de la USP.

Muestreo. Las muestras subgingivales fueron colectadas de las bolsas periodontales y surcos gingivales sanos. Inicialmente, en todos los participantes, se procedió a la remoción la placa supragingival con auxilio de curetas periodontales del tipo Gracey (No. 11/12 para incisivos y No. 17/18 para molares). En seguida, las placas subgingivales de esos sitios, fueron colectadas con auxilio de tres conos de papel absorbente esterilizados (No. 40, Endopoints Ind. Com. Ltda., Rio de Janeiro, RJ, Brasil), siendo introducidos en la región más apical posible de la bolsa periodontal o del surco gingival, permaneciendo por 60 segundos, e inmediatamente transferidos para tubos con 3,5 $\mathrm{ml}$ de medio de transporte VMGA III (viability maintaining microbiostatic medium III) ${ }^{17}$.

Aislamiento e identificación bacteriana. Las muestras clínicas fueron homogenizadas en agitador vortex, y se realizaron diluciones seriadas en solución de dilución VMG I. Alícuotas de $0,1 \mathrm{ml}$ de cada dilución, fueron transferidas, en duplicada, para medio selectivo agar tripticasa de soya con suero de caballo, bacitracina y vancomicina (TSBV) ${ }^{18}$. En seguida, las placas sembradas fueron incubadas en condiciones de anaerobiosis $\left(90 \% \mathrm{~N}_{2}+10 \% \mathrm{CO}_{2}\right)$, a $37^{\circ} \mathrm{C}$, por cuatro días ${ }^{19}$.

La identificación presuntiva para $A$. actinomycetemcomitans fue realizada en el medio selectivo TSBV, observándose con auxilio de lupa estereoscópica la presencia de colonias con diámetros de aproximadamente $0,5 \mathrm{~mm}$ a $1 \mathrm{~mm}$, con márgenes y superficies ligeramente irregulares, aspecto interno característico en forma de estrella o puros cruzados, y fuertemente adheridas al medio de cultivo.

Fusobacterium nucleatum formó colonias de apariencia granular, cenizas, enteras, convexas, con diámetro de 3 $\mathrm{mm}$ a $4 \mathrm{~mm}$, y fácilmente removidas del medio de cultivo. Posteriormente, a partir del cultivo puro de ambos microorganismos en medio agar tripticasa de soya, fueron realizadas la coloración de Gram y la producción de catalasa, así como la determinación del tipo respiratorio, producción de $\mathrm{H}_{2} \mathrm{~S}$, indol, y la sensibilidad al fluorito de sodio $(100 \mu \mathrm{g} / \mathrm{ml})^{7,20}$.

Tabla 1. Características de los pacientes con periodontitis e individuos sanos

\begin{tabular}{|c|c|c|c|c|}
\hline \multirow[t]{2}{*}{ Características } & \multicolumn{2}{|c|}{$\begin{array}{l}\text { Pacientes con periodontitis } \\
\qquad(\mathrm{n}=50)\end{array}$} & \multicolumn{2}{|c|}{$\begin{array}{l}\text { Pacientes sanos } \\
\qquad(n=50)\end{array}$} \\
\hline & Média (\%) & Intervalo & Média (\%) & Intervalo \\
\hline Edad (años) & 48,5 & $21-64$ & 32,4 & $19-48,5$ \\
\hline Diente (nro.) & 25,1 & $11-47$ & 13,0 & - \\
\hline Bolsa periodontal (mm) & 8,6 & $6-13$ & - & - \\
\hline Nivel de inserción periodontal (mm) & 6,7 & $5-7$ & 1,5 & $1,3-3,1$ \\
\hline Puntuaciones de sangrado de toda la boca (\%) & 61,2 & $60-82$ & 17,2 & $17-38$ \\
\hline Puntuaciones de placa de toda la boca (\%) & 60,3 & $48-75$ & 51 & $50-63$ \\
\hline
\end{tabular}


La identificación definitiva a nivel de especie fue realizada por métodos bioquímicos por la fermentación de carbohidratos (1\%), en medio peptona-extracto de levadura (PY), utilizándose dextrosa, maltosa, manitol y xilosa, para identificar $A$. actinomycetemcomitans, y glucosa, galactosa, lactosa, sacarosa y fructosa, para $F: n u-$ cleatum ${ }^{21}$. Todas las cepas de $A$. actinomycetemcomitans y $F$. nucleatum aisladas e identificadas, fueron guardadas congeladas en leche desnatada (10\% - Difco) a $-70{ }^{\circ} \mathrm{C}$ y por liofilización.

Como controles positivos, fueron utilizadas cepas de referencia: A. actinomycetemcomitans ATCC 29522, A. actinomycetemcomitans ATCC 33384, $A$. actinomycetemcomitans ATCC 43718, y F. nucleatum ATCC 10953.

Biotipificación de las cepas de $A$. actinomycetemcomitans. El biotipaje de A. actinomycetemcomitans fue determinado por la variación de los valores obtenidos en processo de fermentación de la dextrosa, maltosa, xilosa, y manitol, conforme descrito en la literatura ${ }^{19}$.

Detección molecular de $A$. actinomycetemcomitans y F. nucleatum por la reacción en cadena de la polimerasa (PCR). Las muestras clínicas colectadas y transportadas en medio VMGA III, fueron homogenizadas, y $300 \mu \mathrm{l}$ fueron transferidos para tubo eppendorf, adicionándose $300 \mu \mathrm{l}$ de $\mathrm{H}_{2} \mathrm{O}$ ultra-pura Milli-Q esterilizada. En seguida, las muestras fueron lavadas tres veces con $\mathrm{H}_{2} \mathrm{O}$ Milli-Q, por centrifugación (10,000 x $g, 10$ minutos), y el sedimento fue re-suspendido en $300 \mu \mathrm{l} \mathrm{de} \mathrm{H}_{2} \mathrm{O}$ Milli-Q. Posteriormente, esa suspensión bacteriana fue hervida por 10 minutos, y nuevamente centrifugada, siendo el sobrenadante (DNA) separado y usado inmediatamente, o congelado a $-20{ }^{\circ} \mathrm{C}^{22}$.

Paralelamente, a partir del cultivo bacteriano puro, aproximadamente 10 colonias de $A$. actinomycetemcomitans, y cinco de $F$. nucleatum, fueron re-suspendidas en $500 \mu \mathrm{l}$ de $\mathrm{H}_{2} \mathrm{O}$ Milli-Q, homogenizadas, y hervidas por
10 minutos. En seguida, fueron centrifugadas $(14,000 \mathrm{x}$ $g, 10$ minutos), y el sobrenadante (DNA) fue congelado a $-20{ }^{\circ} \mathrm{C}$, hasta el momento de su uso ${ }^{12}$.

Reacción de amplificación del DNA. Fueron utilizados tres diferentes pares de partidores para A. actinomycetemcomitans y dos pares para $F$. nucleatum descritos en la literatura ${ }^{12,15,23-29}$. El uso de partidores diferentes fue para comprobar su especificidad en la detección de cada una de las bacterias evaluadas. Los partidores fueron sintetizados por Invitrogen (Sáo Paulo, SP), y sus secuencias están presentadas en la Tabla 2.

La reacción de amplificación fue realizada en termociclador (Perkin Elmer, Gene Amp PCR System 2.400), programado para: 1 ciclo de $94^{\circ} \mathrm{C}$, por 5 minutos; 30 ciclos de: $94^{\circ} \mathrm{C}$, por 30 segundos, temperatura de alineamiento para cada partidor (Tabla 2), por 30 segundos, y $72{ }^{\circ} \mathrm{C}$, por 30 segundos; y finalmente, 1 ciclo de $72{ }^{\circ} \mathrm{C}$, por 5 minutos, para extensión final del DNA. En todas las reacciones de amplificación fueron incluidos controles negativos, sin adición del DNA blanco. Las reacciones fueron realizadas en volúmenes finales de 25 $\mu \mathrm{l}$, conteniendo: $8,25 \mu \mathrm{l}$ de $\mathrm{H}_{2} \mathrm{O}$ Milli-Q, $2,5 \mu \mathrm{l}$ de $10 \mathrm{X}$ PCR buffer, $1 \mu \mathrm{l}$ de $\mathrm{MgCl}_{2}(50 \mathrm{mM}), 1 \mu \mathrm{l}$ de $\operatorname{dNTP}(0,2$ $\mathrm{mM}), 1 \mu \mathrm{l}$ de cada partidor $(0,4 \mu \mathrm{M}), 0,25 \mu \mathrm{l}$ de $T a q$ DNA polimerasa $(5 \mathrm{U})$ y $10 \mu \mathrm{l}$ de DNA.

Los productos amplificados de DNA fueron detectados por electroforesis en gel de agarosa (1\%), preparado en solución 1X TBE (tampón Tris-borato, EDTA, pH 8,5) (Invitrogen), en fuente de alimentación (BioRad), a 70 V, por 2 horas. Como control de peso molecular fue utilizado $1 \mathrm{~kb}$ DNA ladder (Gibco BRL). Al término de la electroforesis, el gel fue teñido con solución de bromuro de etidio $(0,5 \mu \mathrm{g} / \mathrm{ml})$. Las bandas fueron observadas y fotografiadas en transiluminador de luz UV con cámara digital (Eletrophoresis Documentation and Analysis System 120, Kodak Digital Science).

Tabla 2. Partidores especies-específicos usados en la detección de Aggregatibacter actinomycetemcomitans y Fusobacterium nucleatum

\begin{tabular}{|c|c|c|c|c|}
\hline Partidores & Secuencia $\left(5^{\prime} 3^{\prime}\right)$ & $\begin{array}{l}\text { Producto } \\
\quad(\mathbf{k b})\end{array}$ & $\begin{array}{l}\text { Temperatura de } \\
\text { alineamiento }\end{array}$ & Referencias \\
\hline \multicolumn{5}{|c|}{ Aggregatibacter actinomycetemcomitans } \\
\hline $\begin{array}{l}\text { ASH1 } \\
\text { AHS2 }\end{array}$ & $\begin{array}{l}\text {-AAA CCC ATC TCT GAG TTC TTC TTC- } \\
\text {-ATG CCA ACT TGA CGT TAA AT- }\end{array}$ & $0,5 \mathrm{~kb}$ & $55^{\circ} \mathrm{C}$ & Ashimoto et al. ${ }^{15}$ \\
\hline $\begin{array}{l}\text { AA1 } \\
\text { AA2 }\end{array}$ & $\begin{array}{l}\text {-CGT GCC AGC AGC CGC GGT AAT ACG- } \\
\text {-CTT TGC ACA TCA GCG TCA G GTA CAT CCC CAA GG- }\end{array}$ & $0,2 \mathrm{~kb}$ & $70 \stackrel{\circ}{ } \mathrm{C}$ & Garcia et al. ${ }^{27}$ \\
\hline $\begin{array}{l}\text { FU1 } \\
\text { FU2 }\end{array}$ & $\begin{array}{l}\text {-GTT TAG CCC TGG TGC CCG AGG- } \\
\text {-TGA CGG GCG GTG TGT ACA AGG- }\end{array}$ & $0,5 \mathrm{~kb}$ & $55^{\circ} \mathrm{C}$ & Macheleidth et al. ${ }^{28}$ \\
\hline \multicolumn{5}{|c|}{ Fusobacterium nucleatum } \\
\hline FN-5047 & $\begin{array}{l}\text {-CAA ATG CTT GTG TCA ATA ATA CT- } \\
\text {-TTT AGA AAT GGT AGA ATA AT- }\end{array}$ & $0,5 \mathrm{~kb}$ & $40^{\circ} \mathrm{C}$ & Avila-Campos et al. ${ }^{12}$ \\
\hline $5059-S$ & $\begin{array}{l}\text {-ATTGG GCT AAA AAT TAT AGTT- } \\
\text {-ACC CTC ACT TTG AGG ATT ATA G- }\end{array}$ & $1 \mathrm{~kb}$ & $40^{\circ} \mathrm{C}$ & Avila-Campos et al. ${ }^{12}$ \\
\hline
\end{tabular}

\footnotetext{
* Nivel de significancia al $1 \%$
} 
Análisis estadístico. Los valores obtenidos en este estudio, fueron analizados por el Índice de Kappa (K) ${ }^{22}$ para verificación de la concordancia entre la detección bacteriana por los métodos de cultivo y PCR, así como también, para demostrar la especificidad y sensibilidad de los ensayos utilizados en la detección de los organismos evaluados.

\section{Resultados}

Por el método de cultivo, de las 50 muestras analizadas de P, 9 (18\%) fueron positivos para A. actinomycetemcomitans, aislándose 19 cepas. De la misma forma, 10 (20\%) de esas muestras fueron positivas para $F$. nucleatum aislándose 19 cepas. También, de las 50 muestras analisadas de S, solamente $1(2 \%)$ fue positiva para $A$. actinomycetemcomitans obteniéndose dos cepas, y 12 (24\%) muestras positivas para F. nucleatum obteniéndose 18 cepas.
En la Tabla 3 están expresados los valores, en porcentajes, de sensibilidad y especificidad de los partidores específicos para ambos microorganismos evaluados con relación al método de cultivo. Es notado también que los tres partidores fueron más sensibles en la detección microbiana para muestras de S. El partidor AA mostró sensibilidad de $100 \%$ para las muestras de P y S. Por el cálculo del índice kappa (k) para evaluar el grado de concordancia en la detección de ambos organismos, entre los métodos de cultivo y PCR, fue constatado baja o ninguna concordancia entre los métodos utilizados $(P$ $>0,005)$ (Tabla 4). Para la detección de F. nucleatum la sensibilidad de detección varió de 25 a 50\% y la especificad fue elevada variando de 67 a 97\%.

En la Tabla 4 son mostrados los valores comparativos en la detección de ambos microorganismos evaluados, entre el método de cultivo y la detección por PCR, utilizándose diferentes partidores específicos. También,

Tabla 3. Porcentajes de sensibilidad y especificidad de los partidores específicos utilizados en la detección de Aggregatibacter actinomycetemcomitans y Fusobacterium nucleatum

\begin{tabular}{ccccc}
\hline \multirow{2}{*}{ Partidores } & \multicolumn{2}{c}{ Detección en muestras clínicas } \\
\cline { 2 - 5 } & \multicolumn{2}{c}{$\begin{array}{c}\text { Especificidad }{ }^{* *}(\%) \\
\text { Pacientes }\end{array}$} & Pacientes & Sanos \\
\hline Aggregatibacter actinomycetemcomitans & & & 95 \\
\hline ASH & 5 & 100 & 75 & 15 \\
AA & 100 & 100 & 5 & 60 \\
FU & 77 & 100 & 59 & 87 \\
\hline Fusobacterium nucleatum & & & 67 & 97 \\
\hline FN-5047 & 50 & 34 & 97 & \\
\hline 5059-S & 30 & 25 & & \\
\hline
\end{tabular}

*Sensibilidad (positivo-verdadero) = (Nro. de positivos iguales para PCR y cultivo/Nro. de positivos por cultivo) x 100.

**Especificidad (negativo-verdadero) $=($ Nro. de negativos iguales para PCR y cultivo/ Nro. de negativos por cultivo) $x 100$.

Tabla 4. Valores obtenidos en la evaluación comparativa entre los métodos de cultivo y PCR en la detección de $A$. actinomycetemcomitans y F. nucleatum, en muestras clínicas y en VMGA III

\begin{tabular}{|c|c|c|c|c|c|c|c|c|c|c|c|}
\hline \multirow{4}{*}{ Muestras clínicas(n) } & \multirow{4}{*}{ Cultivo } & \multicolumn{10}{|c|}{ Partidores } \\
\hline & & \multicolumn{6}{|c|}{ A. actinomycetemcomitans } & \multicolumn{4}{|c|}{ F. nucleatum } \\
\hline & & \multicolumn{2}{|c|}{ ASH } & \multicolumn{2}{|c|}{ FU } & \multicolumn{2}{|c|}{ AA } & \multicolumn{2}{|c|}{ FN-5047 } & \multicolumn{2}{|c|}{$5059-S$} \\
\hline & & + & - & + & - & + & - & + & - & + & - \\
\hline \multirow{2}{*}{$\begin{array}{l}\text { Pacientes con periodontitis } \\
\qquad(50)\end{array}$} & +10 & 2 & 7 & 7 & 2 & 9 & 0 & 3 & 7 & 5 & 5 \\
\hline & -40 & 10 & 31 & 17 & 24 & 39 & 2 & 1 & 39 & 13 & 27 \\
\hline $\begin{array}{l}\mathrm{K} \\
(\mathrm{P})\end{array}$ & & \multicolumn{2}{|c|}{$\begin{array}{c}0,019 \\
(0,555)\end{array}$} & \multicolumn{2}{|c|}{$\begin{array}{c}0,220 \\
(0,024)\end{array}$} & \multicolumn{2}{|c|}{$\begin{array}{c}0,018 \\
(0,250)\end{array}$} & \multicolumn{2}{|c|}{$\begin{array}{c}0,355 \\
(0,002)^{*}\end{array}$} & \multicolumn{2}{|c|}{$\begin{array}{c}0,135 \\
(0,151)\end{array}$} \\
\hline \multirow{2}{*}{$\begin{array}{l}\text { Indivíduos sanos } \\
\qquad(50)\end{array}$} & +22 & 1 & & 1 & 0 & 1 & 0 & 3 & 9 & 4 & 8 \\
\hline & -30 & 2 & 47 & 20 & 29 & 42 & 7 & 1 & 37 & 5 & 33 \\
\hline $\begin{array}{l}\mathrm{K} \\
(P)\end{array}$ & & \multicolumn{2}{|c|}{$\begin{array}{c}0,485 \\
(<0,001)^{*}\end{array}$} & \multicolumn{2}{|c|}{$\begin{array}{c}0,055 \\
(0,118)\end{array}$} & \multicolumn{2}{|c|}{$\begin{array}{c}0,007 \\
(0,342)\end{array}$} & \multicolumn{2}{|c|}{$\begin{array}{c}0,221 \\
(0,056)\end{array}$} & \multicolumn{2}{|c|}{$\begin{array}{c}0,290 \\
(0,006)\end{array}$} \\
\hline
\end{tabular}

$\mathrm{K}=$ índice kappa; $\mathrm{P}<0,005=\mathrm{K} \neq 0$

*Valores estadísticamente significativos 
se puede notar que las muestras negativas por cultivo, fueron positivas para la detección bacteriana por PCR, y los partidores ASH y FN-5047 mostraron valores estadísticamente significativos. Por PCR usándose los tres pares de partidores específicos para $A$. actinomycetemcomitans, fueron observadas diferencias en la detección de esta bacteria, tanto para muestras clínicas de $\mathrm{P}$ y $\mathrm{S}$, respectivamente, como sigue: partidor AA, 96\% y $86 \%$; partidor FU, 48\% y 42\%; y partidor ASH, $24 \%$ y $6 \%$. También, los porcentajes de detección de F. nucleatum de las muestras de P y S fueron, respectivamente: partidor FN-5047, 36\% y 18\%; y partidor 5059-S, 8\% para ambas muestras colectadas.

En la Figura 1 se pueden observar los valores de porcentajes de aislamiento para cada organismo estudiado, en los dos grupos de individuos analizados (pacientes y sanos), y por los dos métodos de detección microbiana usados en este estudio. Todas las cepas aisladas de $A$. actinomycetemcomitans y $F$. nucleatum presentaron las características coloniales típicas de cada especie en medio TVBV, y las 21 cepas de $A$. actinomycetemcomitans fueron agrupados en cinco biotipos: II (10 cepas: 8 de P y 2 de S), VI (1 cepa), VIII (4 cepas), IX (1 cepa), y X (5 cepas); siendo el más prevalente, el biotipo II (Figura 2).

En las Figuras 3 y 4 se observan los productos amplificados para $A$. actinomycetemcomitans y $F$. nucleatum, respectivamente, para cada partidor específico utilizado.

\section{Discusión}

En este estudio, fue realizada la detección comparativa de dos importantes microorganismos bucales, participantes de procesos periodontales. Para esto, se comparó el método de cultivo con la utilización del medio selectivo TSBV ${ }^{18}$ específico para el aislamiento de $A$. actinomycetemcomitans. Interesantemente, el uso de este medio de cultivo también permitió el aislamiento $F$. nucleatum con buen crecimiento y preservando sus características coloniales típicas. Esto puede ser explicado por los nutrientes presentes en el medio de cultivo y por la incubación en condiciones de anaerobiosis.

Microorganismos como $A$. actinomycetemcomitans y $F$. nucleatum son importantes componentes de la microbiota residente bucal humana y animal, y tienen participación en varias infecciones mono-microbianas y mixtas, tales como sinusitis, infecciones pélvicas, osteomielitis, abscesos pulmonares y cerebrales, y enfermedad periodontal ${ }^{12,24}$.

Debido al elevado número de microorganismos bucales, particularmente, los periodontopatógenos que pueden ser aislados de un único sitio periodontal, los métodos de identificación y detección microbiana deben ser padronizados. Los progresos obtenidos en el diagnóstico microbiológico periodontal pueden colaborar para el mejor conocimiento del microbioma subgingival, constituyéndose en herramientas auxiliares para el tra-

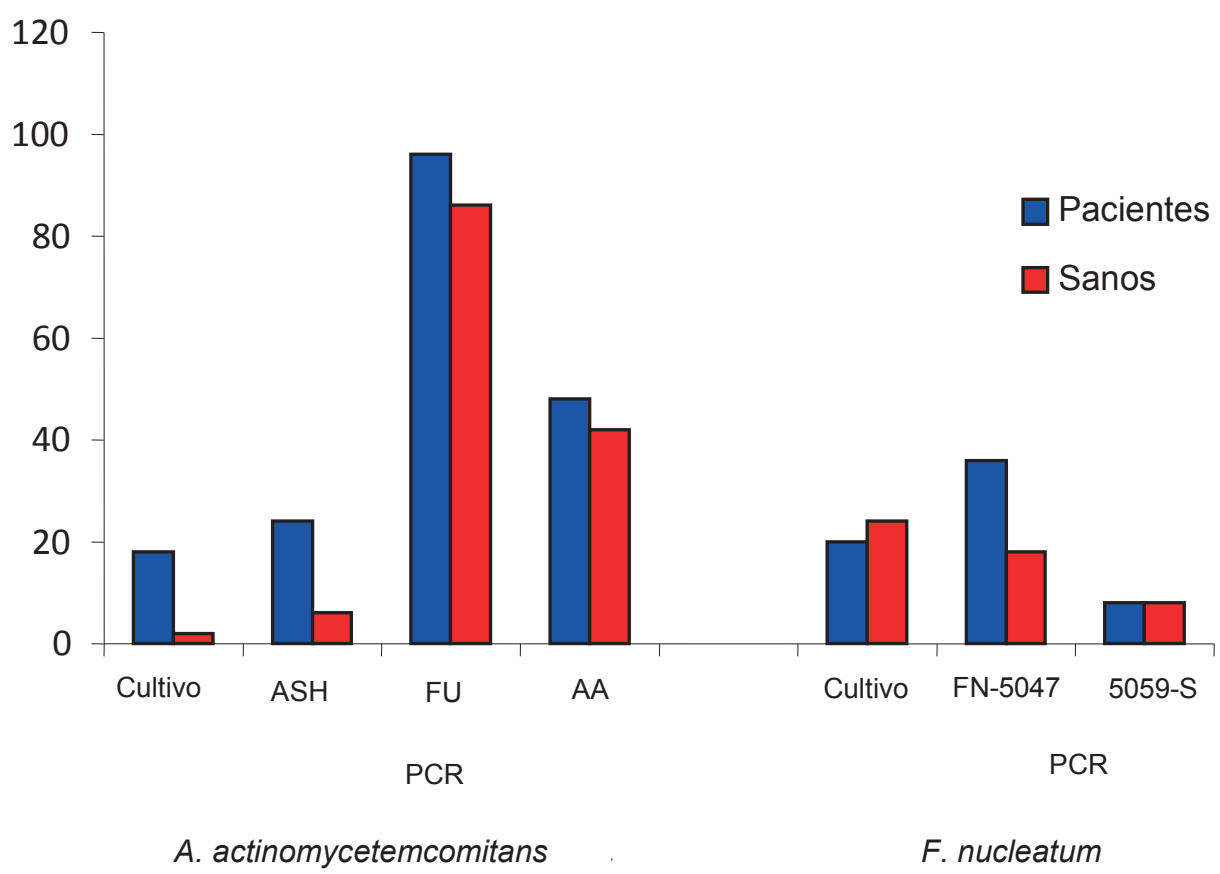

Figura 1. Valores en porcentajes de detección de A. actinomycetemcomitans y F. nucleatum en muestras de bolsa periodontal (pacientes) y surco gingival (sanos), por los métodos de cultivo y PCR, por cada partidor específico (ASH, FU, AA, FN-5047 y 5059-S) utilizado 


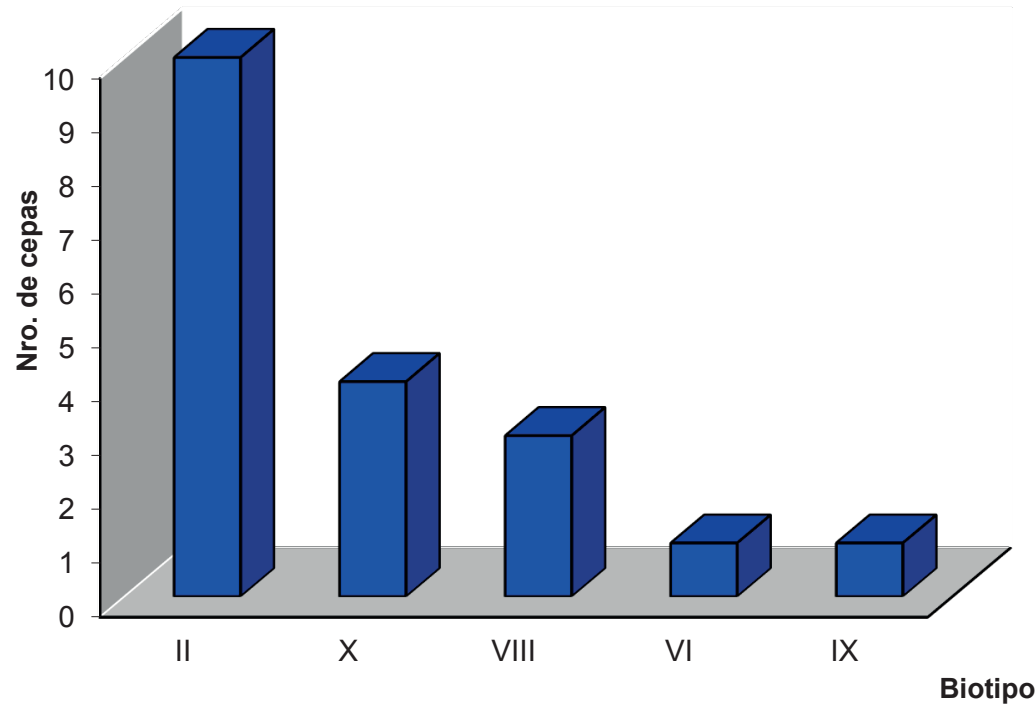

Figura 2. Relación de los biotipos encontrados en las 21 cepas de $A$. actinomycetemcomitans aisladas (19 de P y 2 de S). O biotipo II* (albergó 8 cepas de P y 2 de S)

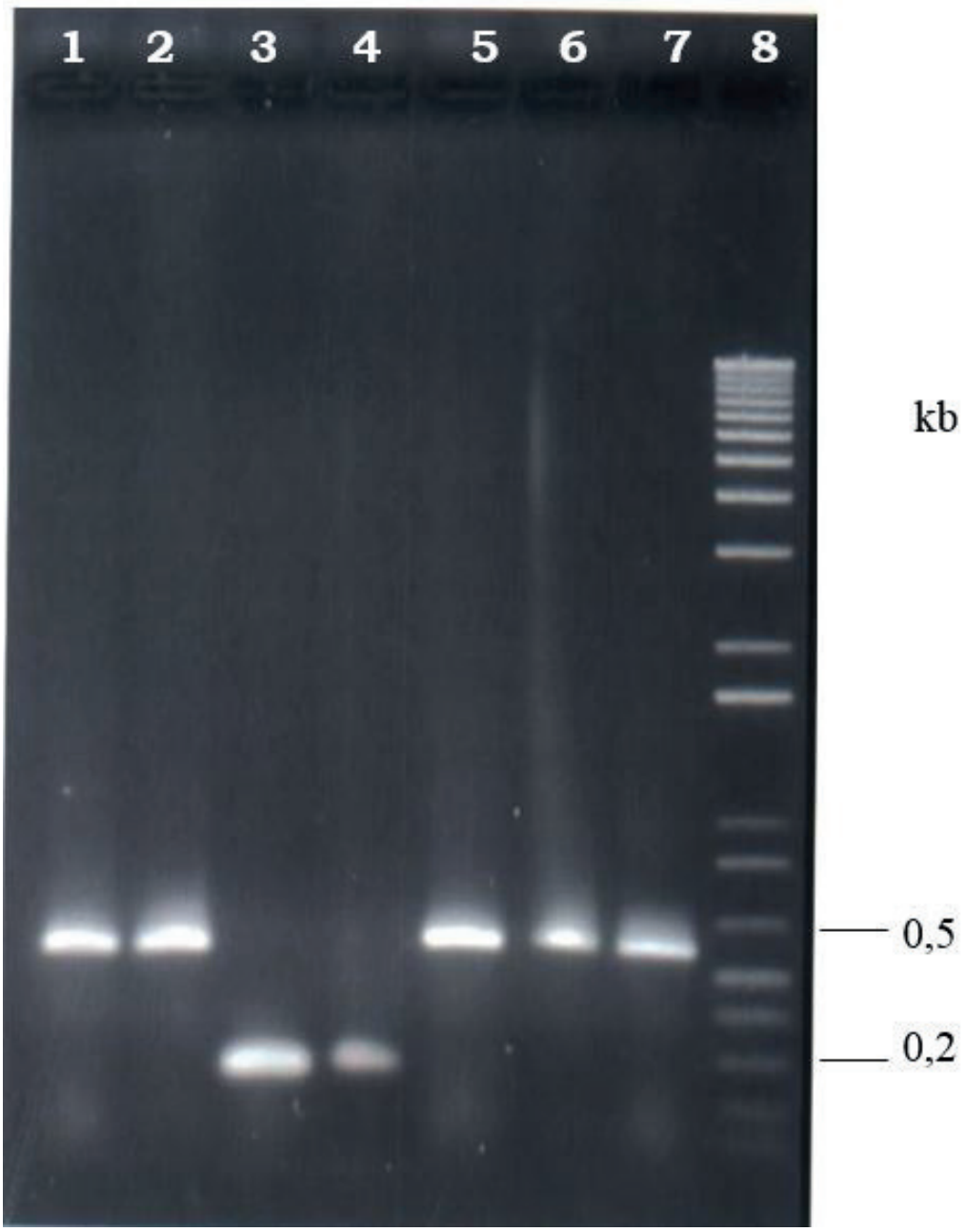

Figura 3. Amplificación del DNA de A. actinomycetemcomitans obtenido de cultivo puro y de VMGA III, respectivamente, utilizando tres diferentes partidores específicos: Líneas 1 y 2, partidor ASH; líneas 3 y 4, partidor AA; líneas 5 y 6, partidor FU; línea 7, $A$. actinomycetemcomitans ATCC 33384, partidor FU; línea 8, marcador de peso molecular de $1 \mathrm{~kb}$ DNA ladder 


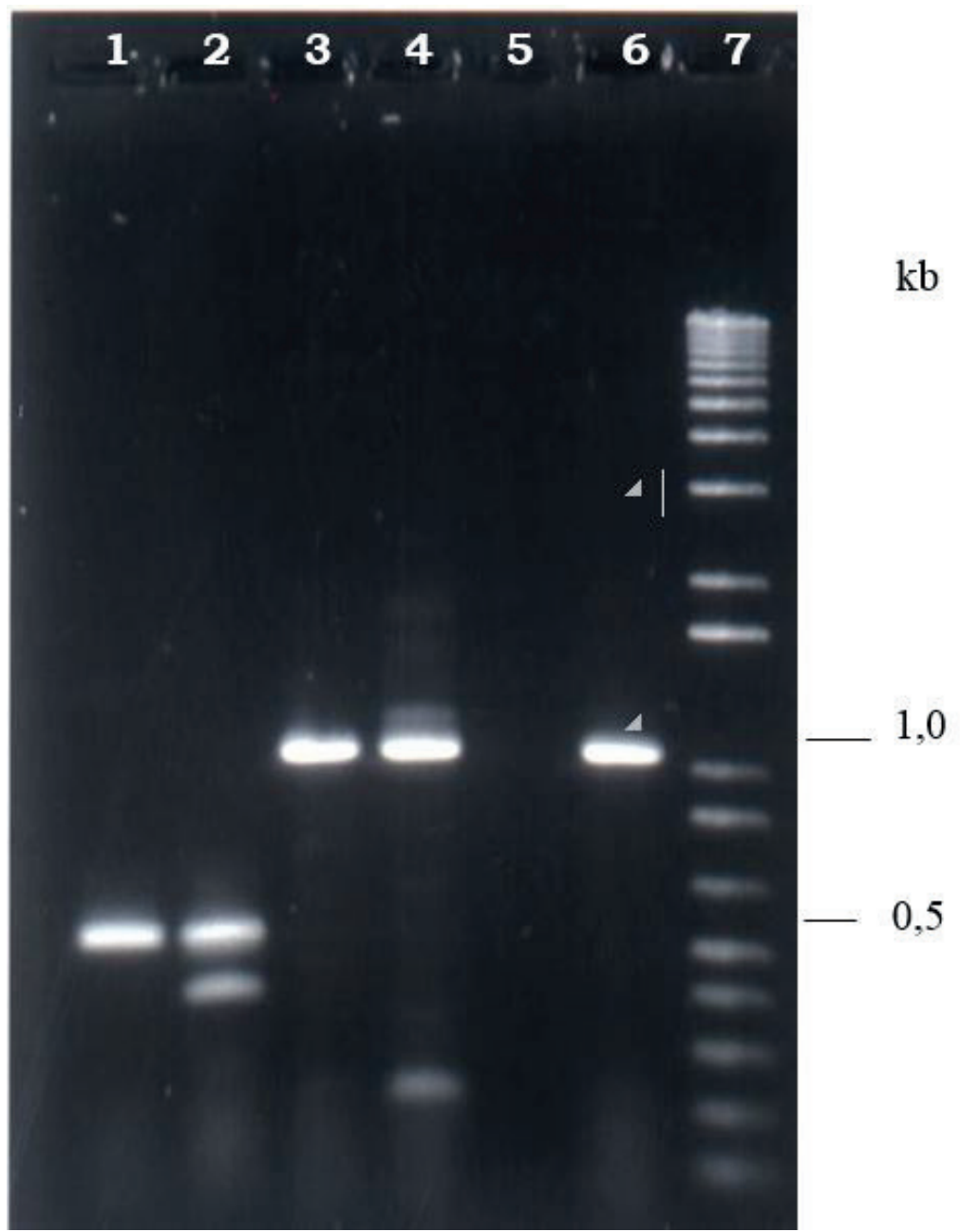

Figura 4. Amplificación del DNA de F. nucleatum obtenido de cultivo puro y de VMGA III, respectivamente, utilizándose dos pares diferentes de partidores específicos: Líneas 1 y 2, partidor FN-5047; líneas 3 y 4, partidor 5059-S; línea 5 , control negativo (utilizando agua esterilizada en lugar del DNA bacteriano); línea 6, F. nucleatum ATCC 10953, partidor 5059-S; línea 7, marcador de peso molecular de $1 \mathrm{~kb}$ DNA ladder

tamiento de las enfermedades periodontales ${ }^{25}$. Es importante resaltar que, el diagnóstico microbiológico, particularmente, para periodontopatógenos anaerobios, todavía no se constituye parte de la rutina de trabajo de los periodoncistas, y su indicación seria necesaria en casos particulares. En el Brasil la identificación de periodontopatógenos por PCR también no es usada rutinariamente.

La literatura muestra que $A$. actinomycetemcomitans presenta 10 tipos bioquímicos diferentes ${ }^{21}$. En este estudio, fue observado que la mayoría de los pacientes albergó un único biotipo, siendo el más prevalente el biotipo II (Figura 2). En el Brasil, Avila-Campos et al. ${ }^{19} \mathrm{y}$ Wahagusi et al. ${ }^{22}$, relataron la predominancia de cepas del biotipo X. Esas diferencias observadas, muestran la diversidad y heterogeneidad de este grupo microbiano. Por otro lado, en el Brasil existe una población multiétnica, con fuerte mezcla de razas y hábitos peculiares y la ocurrencia de diferentes patógenos bucales en biopelícula dental o subgingival puede haber influenciado en estos resultados.
En este estudio, por el método de cultivo, el aislamiento de $A$. actinomycetemcomitans fue observado en $18 \%$ de los pacientes $(\mathrm{P})$ y en $2 \%$ de los sanos $(\mathrm{S})$, concordando con la literatura ${ }^{15}$. Similarmente, F. nucleatum fue aislado en $20 \%$ de los pacientes (P) y en $24 \%$ de los sanos (S). Resultados similares fueron presentados por Nogueira et al. ${ }^{26}$, evaluando la prevalencia de periodontopatógenos en la población Argentina, donde observaron diferencias significativas entre las microbiotas de sitios sanos y enfermos.

Actualmente, la utilización de métodos moleculares, especialmente sondas de DNA y PCR han permitido la identificación rápida de varios microorganismos con gran sensibilidad y especificidad de detección ${ }^{27,28}$. En la detección por PCR, fueron utilizados tres partidores diferentes, observándose discrepancias en el grado de detección para $A$. actinomycetemcomitans (Figura 1), sugiriéndose que la selección de los partidores en la detección microbiana es importante para obtenerse resultados reales. También, por el nivel de esa discrepancia, expresados en porcentajes, los tres partidores utilizados 
para detectar $A$. actinomycetemcomitans mostraron diferencias en la sensibilidad y especificidad (Tabla 3). Esa discrepancia, tanto en sanos como en pacientes, también fue observada con los partidores usados para detectar F. nucleatum.

La utilización del partidor AA para la detección de $A$. actinomycetemcomitans mostró valores elevados, tanto en pacientes como en sanos. Esos datos sugieren que el DNA bacteriano de ese organismo estaba presente en las muestras colectadas, indicando su participación en la microbiota bucal de esos individuos, siendo necesario mayores estudios visando un mejor esclarecimiento sobre la participación de ese grupo microbiano en la microbiota residente de la cavidad bucal humana.

En la detección de $A$. actinomycetemcomitans y $F$. nucleatum no fue posible observar alguna concordancia entre cultivo y PCR. Por otro lado, esa falta de concordancia también fue observada entre los partidores específicos utilizados (Tabla 4). Ciertamente, esto, refuerza la hipótesis de escoger adecuadamente los partidores para la detección de periodontopatógenos, particularmente, aquellos con elevado grado de heterogeneidad, como es el caso de $A$. actinomycetemcomitans y $F$. nucleatum.

También, es importante mencionar que las discrepancias cuanto a los valores de sensibilidad y especificidad mostrados en los diferentes estudios, pueden ser explicadas por las diferentes condiciones de procesamiento y obtención de DNA, reactivos utilizados, y hasta la experiencia del operador.

En términos odontológicos, las técnicas de biología molecular han eliminado la necesidad del cultivo bacteriano en el análisis de muestras de biopelículas subgingivales, contribuyendo para la obtención de un diagnóstico rápido y para un mejor monitoramiento de las enfermedades infecciosas bucales, pudiendo ser detectados microorganismos directamente del material clínico, hasta aquellos, considerados exigentes o de difícil cultivo, o no cultivables ${ }^{29}$. En conclusión, la utilización de métodos moleculares como PCR en la detección de microorganismos bucales directamente de las muestras clínicas de la cavidad bucal, representa una nueva era en la odontología contemporánea.

\section{Agradecimientos}

Los autores agradecen al Mg. Donald Ramos Perfecto por la revisión del español.

\section{Referencias bibliográficas}

1. Fabris AS, DiRienzo JM, Wikstrom M, Mayer MP. Detection of cytolethal distending toxin activity and $c d t$ genes in Actinobacillus actinomycetemcomitans isolates from geographically diverse populations. Oral Microbiol Immunol. 2002;17:231-238.

2. Reynolds MA. Modifiable risk factors in periodontitis: at the intersection of aging and disease.Periodontol 2000. 2014;64:7-19.

3. Edwardsson S, Bing M, Axtelius B, Lindberg B, Soderfeldt B, Attstrom R. The microbiota of periodontal pockets with different depths in therapy-resistant periodontitis. J Clin Periodontol. 1999; 26(3):143-152.

4. Cortelli JR, Roman-Torres CV, Aquino DR, Franco GC, Costa FO, Cortelli SC. Occurrence of Aggregatibacter actinomycetemcomitans in Brazilians with chronic periodontitis. Braz Oral Res. 2010;24:217-223.

5. Meyer DH, Fives-Taylor PM. The role of Actinobacillus actinomycetemcomitans in the pathogenesis of periodontol disease. Trends Microbiol. 1997;5:224-228.

6. Haubek D, Johansson A. Pathogenicity of the highly leukotoxic JP2 clone of Aggregatibacter actinomycetemcomitans and its geographic dissemination and role in aggressive periodontitis. J Oral Microbiol. 2014;6:1-11.

7. Avila-Campos MJ. Actinobacillus actinomycetemcomitans: Aspectos ecológicos, fisiológicos e susceptibilidade a antimicrobianos. [Dissertação de Mestrado]. [Belo Horizonte]: Instituto de Ciências Biomédicas da Universidade Federal de Minas Gerais;1986.

8. Moore WEC, Moore LVH. The bacteria of periodontal diseases. Periodontol 2000. 1994;5:66-77.

9. Kolenbrander PE, London J. Adhere today, here tomorrow: oral bacteria adherence. J Bacteriol. 1993;175(11):3247-3252.

10. Chen C, Slots J. Microbiological tests for Actinobacillus actinomycetemcomitans and Porphyromonas gingivalis. Periodontology 2000. 1999;20:53-64.

11. Alsina M, Olle E, Frias J. Improved, low-cost selective culture medium for Actinobacillus Actinomycetemcomitans. J Clin Microbiol. 2001;39(2):509-513.

12. Avila-Campos MJ, Sacchi CT, Whitney AM, Steigerwalt AG, Mayer LW. Arbitrarily primed-polymerase chain reaction for identification and epidemologic subtyping of oral isolates of Fusobacterium nucleatum. J Periodontol. 1999;70(10):1202-1208.

13. Lopéz NJ. Occurrence of Actinobacillus actinomycetemcomitans, Porphyromonas gingivalis, and Prevotella intermedia in progressive adult periodontitis. J Periodontol. 2000;71(6):948-954.

14. Slots J, Ashimoto A, Flynn MJ, Li G, Chen C. Detection of putative periodontal pathogens in subgingival specimens by $16 \mathrm{~S}$ ribosomal DNA amplification with the polymerase chain reaction. Clin Infect Dis. 1995;20(2):S304-307.

15. Ashimoto A, Chen C, Bakker I, Slots J. Polymerase chain reaction detection of 8 putative periodontal pathogens in subgingival plaque of gingivitis and advanced periodontitis lesions. Oral Microbiol Immunol. 1996;11(4):266273.

16. Tonetti MS, Greenwell H, Kornman KS. Staging and grading of periodontitis: Framework and proposal of a new classification and case definition. J Periodontol. 2018;89(1):S159-S172. https://doi.org/10.1002/ JPER.18-0006.

17. Möller AJR. Microbiological examination of root canals and periapical tissues of human teeth. Odontol Tidskr. 1966;74:1-38.

18. Slots J. Selective medium for isolation of Actinobacillus actinmycetemcomitans. J Clin Microbiol. 1982;15(4):606-609. 
19. Avila-Campos MJ, Carvalho MAR, Zelante F. Distribution of biotypes and antimicrobial susceptibility of Actinobacillus actinomycetemcomitans. Oral Microbiol Immunol. 1995;10(6):382-384.

20. Gaetti-Jardim JRE. Aspectos ecológicos, fisiológicos e susceptibilidade a antimicrobianos de espécies orais de Fusobacterium. [Dissertação de Mestrado]. [São Paulo]: Instituto de Ciências Biomédicas da Universidade de São Paulo; 1994.

21. Slots J. Salient biochemical characters of Actinobacillus actinomycetemcomitans. Arch Microbiol. 1982;131(1):60-67.

22. Wahasugui TC, Nakano V, Piazza RM, Avila-Campos MJ. Phenotypic and genotypic features of Aggregatibacter actinomycetemcomitans isolated from patients with periodontal disease. Diagn Microbiol Infect Dis. 2013;75:366-372.

23. Maclure M, Willet WC. Misinterpretation and misuse of the Kappa statistic. Amer J Epidemiol. 1987;126(2):161-169.

24. Rodrigues VAA, de Avila ED, Nakano V, Avila-Campos MJ. Qualitative, quantitative and genotypic evaluation of
Aggregatibacter actinomycetemcomitans and Fusobacterium nucleatum isolated from individuals with different periodontal clinical conditions. Anaerobe. 2018;52:50-58.

25. Zambon JJ, Haraszthy VI. The laboratory diagnosis of periodontal infections. Periodontol 2000. 1995;7:69-82.

26. Nogueira-Moreira A, Fernandez-Canigia L, Furman C, Chiappe V, Marcantoni M, Bianchini H. Clinical and microbiological study of adult periodontal disease. Rev Argent Microbiol. 2001;33(3):133-140.

27. Weisburg WG, Barns SM, Pelletier DA, Lane DJ. 16S Ribosomal DNA amplification for phylogenetic study. J Bacteriol. 1991;173(2):697-703.

28. Garcia L, Tercero JC, Legido B, Ramos JA, Alemany J, Sanz M. Rapid detection of Actinobacillus actinomycetemcomitans, Prevotella intermedia and Porphyromonas gingivalis by multiplex PCR. J Periodont Res. 1998;33:59-64.

29. Macheleidt A, Muller HP, Putzker M, Zoller L. Clonal diversity of Actinobacillus actinomycetemcomitans isolates from young adults with minimal periodontal disease. J Periodont Res. 1999;34(4):179-187. 